\title{
Uterine didelphys with obstructed hemivagina and ipsilateral renal anomaly - OHVIRA syndrome: a rare congenital anomaly
}

\author{
Bhimarao Patil, Rashmi Mysore Nagaraju*
}

Department of Radio-Diagnosis, P K Das Institute of Medical Sciences, Palakkad, Kerala, India

Received: 28 March 2015

Accepted: 09 May 2015

\section{*Correspondence:}

Dr. Rashmi Mysore Nagaraju,

E-mail: rashmi83nagaraj@gmail.com

Copyright: (C) the author(s), publisher and licensee Medip Academy. This is an open-access article distributed under the terms of the Creative Commons Attribution Non-Commercial License, which permits unrestricted non-commercial use, distribution, and reproduction in any medium, provided the original work is properly cited.

\begin{abstract}
OHVIRA or Herlyn-Werner-Wunderlich syndrome is a rare congenital anomaly characterized by uterine anomaly with obstructed hemivagina and ipsilateral renal anomaly. We present a case of 16 year female who presented with cyclical lower abdominal pain. Ultrasonography and computed tomography in this patient revealed classic triad of findings. Our case is significant as the diagnosis was made at an earlier stage of the disease before development of gross obstruction and hematometrocolpos.
\end{abstract}

Keywords: OHVIRA, Herlyn-Werner-Wunderlich syndrome, Uterine anomaly, Obstructed hemivagina, Ipsilateral renal anomaly, Hematometrocolpos

\section{INTRODUCTION}

Obstructed hemivagina and ipsilateral renal anomaly (OHVIRA) syndrome with uterine anomaly is a rare congenital disorder. Incidence of mullerian duct anomalies ranges from $0.8 \%$ to $4 \%$ and the incidence of the OHVIRA syndrome is estimated to be between 0.1 $3.5 \%$ of all mullerian anomalies. ${ }^{1}$

Patient is usually a young girl presenting with dysmenorrhea. As regular menstruation with normal flow from the unobstructed side continues, diagnosis is frequently delayed. Early diagnosis and excision of the vaginal septum will relieve the patient of her symptoms and also prevents subsequent development of endometriosis and infertility.

We present a case of uterine didelphys with OHVIRA syndrome.

\section{CASE REPORT}

A 16 year unmarried female presented with progressively increasing lower abdomen pain, cyclically associated with onset of menstruation since 3 months. No history of change in menstrual flow, abnormal vaginal discharge and fever. She had attained menarche 3 years back and had regular menstrual cycle till date. She had well developed secondary sexual characteristics appropriate for her age including breast, axillary and pubic hair.

Clinical examination revealed deep pelvic pain. No obvious palpable mass in abdomen or pelvis. The laboratory investigations were normal.

Trans abominal sonography (Figure 1a \& 1b) revealed absent right kidney with compensatory hypertrophy of left kidney. Transabdominal pelvic ultrasonography in axial (Figure 2a \& 2b) and sagittal planes (Figure 3a \& $3 b)$ revealed the didelphys configuration of uterus with two separate uterine corpora and cervical duplication. 
Mild echogenic collection was noted in right endometrial cavity and cervical canal, suggestive of hematometrocolpos. Left sided uterine corpus and cervical cavity was normal with normal endometrial thickness. Both ovaries were normal.
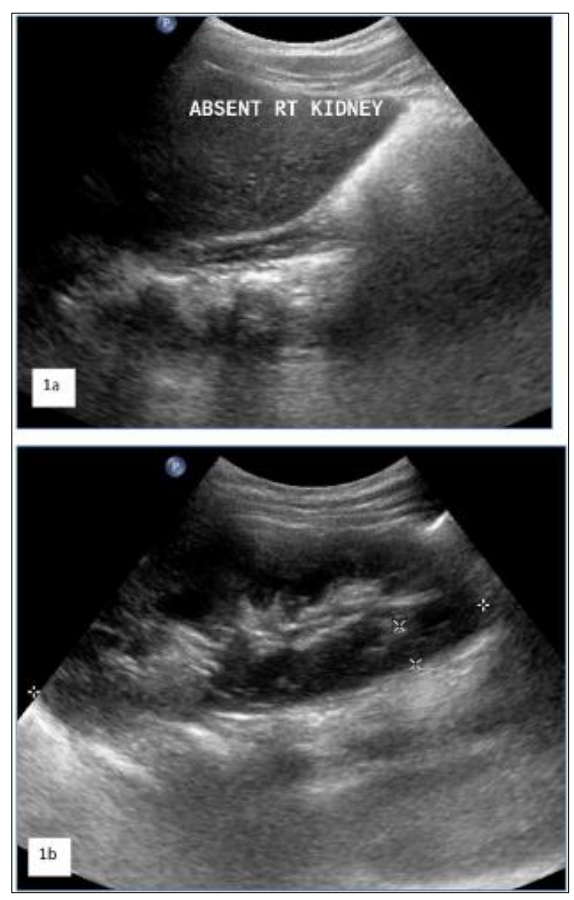

Figure 1 (a \& b): Transabdominal ultrasonography showing absent right kidney (a) and compensatory hypertrophy of left kidney (b).
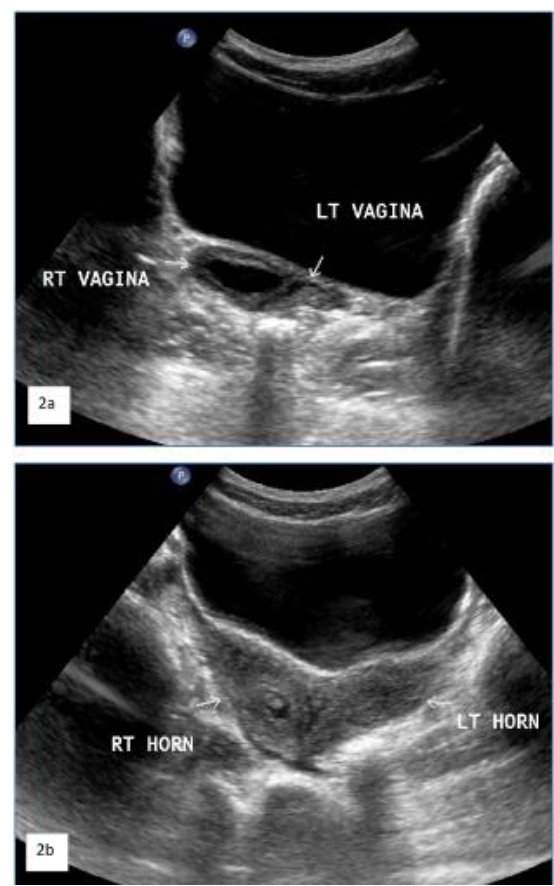

Figure 2 (a \& b): Transabdominal pelvic ultrasonography in axial plane showing 2 cervices \& vaginae (a) and both uterine horns (b) with mild hematometrocolpos.

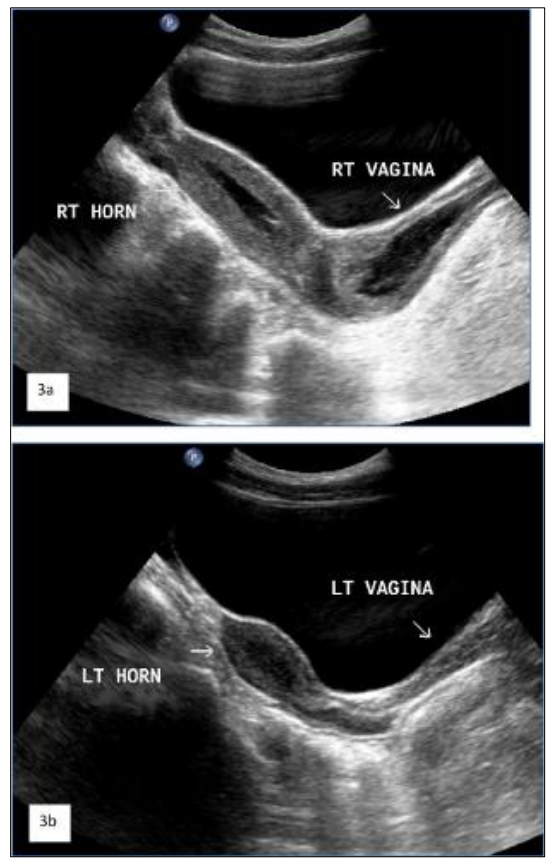

Figure 3 (a \& b): Transabdominal pelvic ultrasonography in sagittal plane showing mild right hematometrocolpos (a) and normal left sided uterine horn and cervix (b).

Plain and contrast enhanced computed tomography revealed absence of right kidney (Figure $4 \mathrm{a} \& 4 \mathrm{~b}$ ). The collection in the right hemivagina and uterine horn was of high attenuation (50-60 HU) suggestive of blood products (Figure 5a \& 5b).
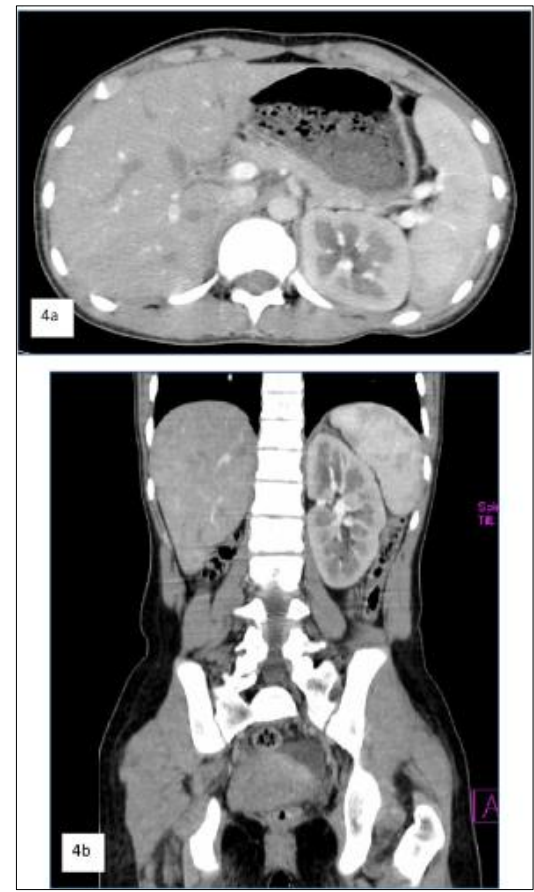

Figure 4 (a \& b): Computed tomography showing absent right kidney (a) and compensatory hypertrophy of left kidney (b). 

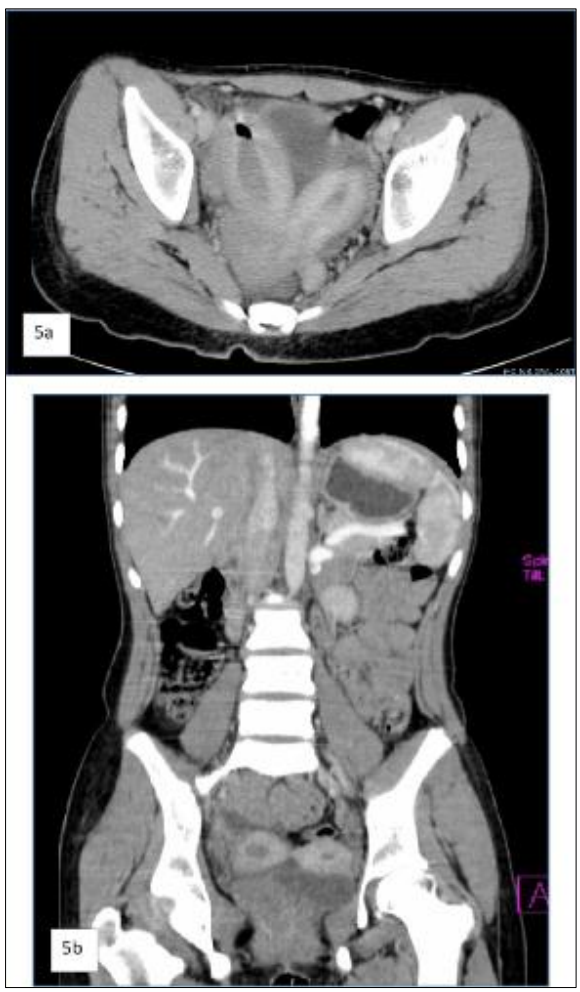

Figure 5 (a \& b): Computed tomography showing didelphys uterus in axial (a) and coronal planes (b).

Thus a diagnosis of uterine didelphys with obstructed right hemivagina with right renal agenesis was made.

She underwent vaginal septostomy and her symptoms were relieved. On follow up after 3 months both the uterine corpora were within normal limits with normal endometrial thickness.

\section{DISCUSSION}

Congenital anomalies of the Müllerian tract are estimated to have an overall prevalence of $2 \%$ to $3 \%$ among women. ${ }^{2}$ Herlyn-Werner-Wunderlich (HWW) syndrome is a triad of obstructed hemi vagina, uterine didelphys and ipsilateral renal anomaly. The acronym OHVIRA is used to describe the triad of obstructed hemi vagina and ipsilateral renal anomaly and any other uterine anomaly other than uterine didelphys. ${ }^{3}$ Both the syndromes are rare and are discussed as same entities in many case reports.

The etiology of the syndrome is unknown. It is thought to be multifactorial and associated with fusion anomalies of Mullerian ducts. ${ }^{4}$

OHVIRA syndrome is rare and delayed diagnosis leads to further compromise of the fertility of the patient. The classical presentation is that of a young girl presenting with severe dysmenorrhea, few months to years after attaining menarche. Retrospective study of cases has shown that the mean age of presentation is about 15 years. ${ }^{5}$ Pelvic pain is the most common presenting symptom (90\%) followed by an abdominal mass (40\%) and pressure symptoms. Patients can also present at a later age with foul smelling vaginal discharge due to pyocolpos. $^{6}$

Ultrasonography is the usual initial imaging modality which is widely available. However MRI gives better characterization of the contents of the endometrial and cervical canal. Also any other associated adnexal pathology is better demonstrated. In case of septate uterus, septa is demonstrated unequivocally by MRI. ${ }^{7-10}$

The standard management of these patients is excision of vaginal septum and drainage of hematometrocolpos. ${ }^{9,10}$

\section{CONCLUSION}

OHVIRA syndrome is a rare complex congenital anomaly of female genital system. A simple excision of the vaginal septum can relieve the patient of her symptoms and avoid compromise of the fertility. Given the rarity of this syndrome it is frequently misdiagnosed or diagnosed late. Delayed diagnosis leads to endometriosis further compromising the fertility potential. Hence greater awareness and early diagnosis with timely intervention can prevent future complications.

\section{Funding: No funding sources Conflict of interest: None declared Ethical approval: Not required}

\section{REFERENCES}

1. Resetkova N, Christianson M, Kolp L. Uterinedidelphys with obstructed hemivagina and ipsilateral renal agenesis with hydronephrosis. Fertil Steril. 2012;97:s30-1.

2. Shavell VI, Montgomery SE, Johnson SC, Diamond MP, Berman JM. Complete septate uterus, obstructed hemivagina, and ipsilateral renal anomaly: pregnancy course complicated by a rare urogenital anomaly. Arch Gynecol Obstet. 2009 Sep;280(3):449-52.

3. Kimble RMN, Kimble RM. The obstructed hemivagina, ipsilateral renal anomaly, uterus didelphystriad. Aust N Z J Obstet Gynaecol. 2009;49:4-7.

4. Bajaj SK, Misra R, Thukral BB, Gupta R. OHVIRA. Uterus didelphys, blind hemivagina and ipsilateral renal agenesis: Advantage MRI. J Hum Reprod Sci. 2012;5:67-70.

5. Christianson MS, Yates MM, Woo I, Khafagy A, Garcia JE, Kolp LA. Obstructed hemivagina and ipsilateral renal anomaly (OHVIRA): diagnostic features and managementof a frequently misdiagnosed syndrome. Fertil Steril. (2012) 98: S222.

6. Dhar H, Yasser AR, Illham H. Uterusdidelphys with obstructed hemi vagina, ipsilateral renal agenesis and right pyocolpos: a case report. Oman Med J. 2011;26:447-50. 
7. Tanaka YO, Kurosaki Y, Kobayashi T, Eguchi N, Mori K, Satoh Y, et al. Uterus didelphys associated with obstructed hemivagina and ipsilateral renal agenesis: MR findings in seven cases. Abdom Imaging. 1998 Jul-Aug;23(4):437-41.

8. Carrington BM, Hricak H, Nuruddin RN, Secaf E, Laros RK Jr, Hill EC. Mullerian duct anomalies: MR imaging evaluation. Radiology. 1990 Sep;176(3):715-20.

9. Jaiprakash T, Saxena RK, Pandey P. Obstructed hemivagina with ipsilateral renal anomaly
(OHVIRA) syndrome - a rare congenital anomaly. J Genit Syst Disord. 2013;2:2.

10. Han B, Herndon CN, Rosen MP, Wang ZJ, DaldrupLink H. Uterine didelphys associated with obstructed hemivagina and ipsilateral renal anomaly (OHVIRA) syndrome. Radiol Case Rep. 2010;5:327.

DOI: 10.18203/2320-1770.ijrcog20150121

Cite this article as: Patil B, Nagaraju RM. Uterine didelphys with obstructed hemivagina and ipsilateral renal anomaly - OHVIRA syndrome: a rare congenital anomaly. Int J Reprod Contracept Obstet Gynecol 2015;4:889-92. 